\title{
Chapter 29 \\ Constructing Dynamic Geometry: Insights from a Study of Teaching Practices in English Schools
}

\author{
Kenneth Ruthven
}

\begin{abstract}
Any technology retains a degree of fluidity in its conception, shaped not just by its designers but by its subsequent users. This chapter applies this perspective to one form of software which has attracted particular attention in mathematics teaching: dynamic geometry. Drawing on a study conducted in professionally well-regarded mathematics departments in English secondary schools, the chapter sketches the wider curricular context, provides an overview of each of three contrasting cases of teaching practices making use of dynamic geometry, and presents cross-cutting themes through which these contrasts can be characterised. Critical variables include the degree to which teachers see student use of the software as promoting mathematically-disciplined interaction, analysis of apparent mathematical anomalies as supporting learning, and dragging as a means of focusing attention on continuous variation. The chapter concludes by discussing how teaching practices might productively be developed, and how such development might be supported by further research.
\end{abstract}

Keywords Case study $\cdot$ Dynamic geometry $\cdot$ School mathematics Teaching practices $\cdot$ Technology integration

\subsection{Overview}

In recent years, dynamic geometry has attracted attention in mathematics education. However, like any mathematical software, it leaves the user considerable scope to interpret how it might serve as a curricular and pedagogical resource. After sketching the wider context, this chapter outlines three illustrative cases of teaching practices featuring use of dynamic geometry in lower-secondary mathematics lessons in English schools (drawn from Ruthven et al. 2008). Initially, the focus is on

K. Ruthven $(\square)$

Faculty of Education, University of Cambridge, 184 Hills Road,

Cambridge CB2 8PQ, UK

e-mail:kr18@cam.ac.uk

(C) The Author(s) 2018

G. Kaiser et al. (eds.), Invited Lectures from the 13th International Congress

on Mathematical Education, ICME-13 Monographs,

https://doi.org/10.1007/978-3-319-72170-5_29 
the way in which the teacher within each case characterises their teaching practice and offers a supporting rationale for it. Next, taking a researcher perspective informed by relevant literatures, these cases are compared in terms of cross-cutting themes intended to capture commonalities and contrasts between them. The chapter concludes by discussing how teaching practices might productively be developed further, and how such development might be supported.

\subsection{The Evolving Design of Dynamic Geometry and Framing of Its Use}

In the field of social studies of technology, the idea of 'interpretative flexibility' (Kline and Pinch 1999) acknowledges that conception of a technology remains fluid beyond the initial stage of the design of a product, continuing into the subsequent stage in which it is taken up by users. The ways in which a technology is employed become aligned with user concerns and adapted to the situations in which use takes place. This opens the way to variation in modalities of use between different user groups and between different settings for use, and to change in these modalities over time. Similarly, in research on the diffusion of educational resources, it has come to be recognised that teachers act as interpreters and mediators of curriculum materials (Remillard 2005). Teachers typically select from and adapt curriculum materials, and they necessarily incorporate these materials into wider systems of classroom practice (Ball and Cohen 1996). Both these traditions, then, highlight the scope for interpretation of an innovative resource such as dynamic geometry

Two particular packages served to define the new class of software which came to be known as 'dynamic geometry'. Geometer's Sketchpad was originally conceived simply as a program "to draw accurate, static figures from Euclidean geometry" (Goldenberg et al. 2008, p. 58). In the course of its development, however, the idea of creating a dynamic - rather than static-figure was borrowed from contemporary drawing software, so that points and segments of a figure could be dragged while preserving the properties defining it. Inspired by earlier software for visualizing discrete graphs, dragging was designed into Cabri Geometry from the start, although views on its significance differed considerably (Laborde and Laborde 2008). Relatively rapidly, however, dragging became accepted as the key defining feature of dynamic geometry software.

Although dynamic geometry systems were developed with educational purposes in view, neither Cabri nor Sketchpad was initially devised with a particular pedagogical approach in mind (Goldenberg et al. 2008). However, pioneering work by mathematics educators associated dynamic geometry with a pedagogical orientation in which such software served "to create experimental environments where collaborative learning and student exploration are encouraged" (Chazan and Yerushalmy 1995, p. 8). Nevertheless, a substantial national survey conducted in the United States (Becker et al. 1999) conveyed a rather different picture. Although 
Sketchpad was chosen by more than one in five high school mathematics teachers who nominated a 'most valuable' software title, further evidence indicated an association between teachers nominating Sketchpad and reporting skill-development as their main objective for computer use (p. 46). This suggests, then, that modes of use of dynamic geometry in mainstream classrooms may differ markedly from the exploratory orientation advocated by many proponents.

Much of the pioneering development of dynamic geometry systems took place in countries - notably France and the United States - which have retained a more strongly Euclidean spirit within their school geometry curriculum (Hoyles et al. 2001). This Euclidean lineage of dynamic geometry might be expected to fit poorly with a national curriculum which refers - as did the English one framing the practice to be studied here-not to Geometry but to Shape, Space and Measures. However, the scope to employ the software as a means of supporting observation and measurement resonates with a longstanding orientation of English school mathematics. In her comparative ethnography, Kaiser (2002) noted the predominance in English mathematics classrooms of example-based checking as a means of validating results, not just employed by students, but also encouraged by their teachers. Exemplifying this trend, she cites a lesson in which one of the 'circle theorems' was established by the teacher setting each student to draw and measure three diagrams to test the result, and then arguing for its acceptance on the strength of these accumulated checks.

At the time of the study to be discussed, some use of dynamic geometry at lower-secondary level had been given official endorsement and more detailed expression in a government-sponsored elaboration of the English national curriculum (Department for Education and Employment 2001). The emphasis of many of the illustrations was on empirical exploration, but some examples presented observation of a dynamic figure as a precursor to proving with static diagrams. While this official guidance explicitly recognised the knowledge required to use classical manual tools for the construction and measurement of geometric figures, it overlooked equivalent aspects of using dynamic software. For instance, while the knowledge required to make use of a protractor to measure angles by hand was carefully specified, no attention was given to the distinctive knowledge required to measure angles with dynamic software.

\subsection{Study Design}

The objective of this study was to understand what mathematics teachers at lower-secondary level in England regarded as successful use of dynamic geometry. To address this objective, a multiple case-study design was chosen, employing methods which aimed at characterising teachers' thinking and practice, first in their own terms, and then in terms of broader constructs informed by the research literature. The cases which I discuss here were identified through a process intended to elicit professionally well-regarded practice in using digital tools in mathematics 
teaching. Relatively few schools nominated on this basis reported making use of dynamic geometry: cases were then chosen for further study so as to capture the range of approaches reported and to follow up teachers who had been particularly informative. Data portfolios for each case were assembled through a procedure involving classroom observation followed up by teacher interview, including the copying of associated curricular resources. These portfolios were analysed thematically in two stages. The first stage of analysis was within-case, adopting an emic approach intended to capture and distil into a case narrative the terms in which the teacher responsible characterised and explained the case and offered a supporting rationale for it. The second stage was cross-case, adopting an etic approach, taking a researcher perspective informed by relevant literature, and aimed at identifying important commonalities and contrasts across cases. Full details of the design of the study and methods employed can be found in the original report (Ruthven et al. 2008). Equally, the individual case narratives and the cross-case analysis are reported there in full.

\subsection{Case Outlines}

These case outlines (adapted from Ruthven et al. 2008; Ruthven 2012) summarise each case in terms of the main emic themes identified in the analysis (as indicated by the titles of subsections). They characterise the practice associated with each case as elaborated by the teacher responsible. Each case is summarised in terms of four main themes, encapsulated in the subsection titles and then expressed in the teacher's own words.

\subsubsection{Case $N$}

This example, focusing on angle properties in the circle (see Fig. 29.1), was nominated in these terms by the teacher concerned:

The one that I do like to do is the one with the circle theorem that says the angle at the centre is twice the angle at the circumference, because that covers the same theorem as the angles in the same segment, and the angle at the semi-circle is 90 degrees, and you can cover a lot of different circle theorems by doing that one demonstration. And the students find it very, very difficult to believe if they don't see it on the computer... And yet when you're dragging it round this circle using Cabri... it just gets that they start to believe a lot more and they are more convinced of its truth.

A corresponding 40-minute lesson started with 25 minutes of activity led by the teacher, during which he constructed and manipulated a dynamic figure, projected from his computer onto an ordinary whiteboard. This was followed by individual student activity on a (pencil and paper) textbook exercise. 
Fig. 29.1 Figure used in Case $\mathrm{N}$ lesson

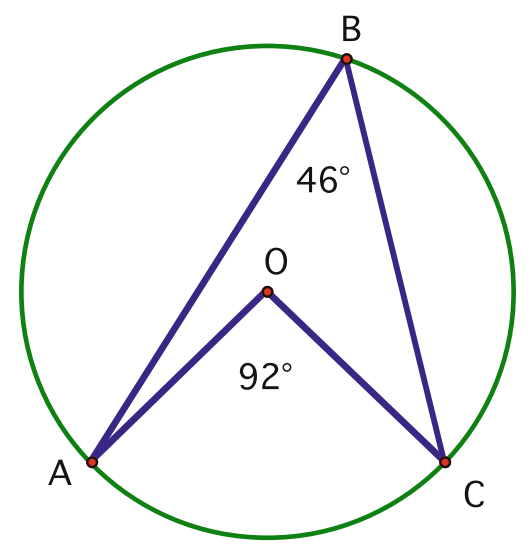

\subsubsection{Maintaining Students' Attention and Lesson Progression Through Dynamic Presentation and Tactical Questioning}

The teacher valued dynamic geometry presentation for holding the attention of students:

I think that holds their attention more. The fact that they can see that you can pick up and drag these shapes around, and then the angles change as well automatically, so all the numbers are changing... That sort of movement, that dynamism, helps to keep their attention.

He used tactical questioning of carefully chosen students with a view to supporting the progression of the whole-class segment of the lesson towards a target result:

[I] pick on students that I think may have a problem with it... If students that I think are going to have a problem with it understand it, then I can be fairly confident that the others understand it as well... If [I] ask a student a question and they don't know the answer, I won't give up on them, I'll carry on asking or trying to get the correct response out of them... Not only is it benefiting the student you've asked, everybody else is trying to come to the correct solution as well. And so I do that to help reinforce what's being presented.

\subsubsection{Making Properties Apprehensible and Convincing to Students Through Purposive Dragging}

The teacher saw purposive dragging of the figure as a powerful means through which he could make properties - such as the unchanging measure of the angle at the circumference - apprehensible and convincing to students:

If you do it on the board and you drag the thing round, then they tend to be much more convinced by what they see. So, I think the technology helps because they can actually see it getting dragged round, they see the angle doesn't change and they are much more convinced. 
To make underlying relationships between changing measures - such as between the angle at the circumference and the angle at the centre-discernible by students, the teacher led a process of dragging the figure to generate pairs of values from which students themselves could identify the target pattern:

Trying to get across the point that the angle at the centre is twice the angle at the outside... Because the angle automatically changes as you drag the point round, you can write up pairs of values, [and] the students can deduce that themselves... So the technology helps a great deal in that respect because you're not just telling them a fact, you're allowing them to sort of deduce it and interact with what's going on.

\subsubsection{Making It Easy for Students to Identify Properties by Pre-empting Possible Confusions}

The teacher took great care to anticipate and pre-empt situations which might confuse students:

[I] keep things running through the lesson in my own head, and looking for possibilities where students may become confused, or things that might cloud the issue, so that I can do something about that before it becomes an issue in the classroom.

In particular, he designed the dynamic figures that he used and manipulated them in ways intended to make target properties as readily discernible by students as possible:

I obviously pre-prepared the circle with the lines and angles already marked in. Also for this group, I made sure the angles were always integer values... That way you don't have half angles to deal with. So the angle at the centre was always an even number of degrees because that way the angle at the outside can be halved quite successfully... So I did that to help make it a little bit easier for them to spot the rule.

For example, the teacher avoided dragging figures into positions where an angle - such as the angle at the centre of the circle-would become reflex, resulting in the measure of its smaller counterpart angle being shown by the software:

When you move things around, if the three points you are measuring swap over somehow, then it starts measuring a different angle.

\subsubsection{Avoiding the Disadvantages of Software Use by Students Through Teacher Presentation}

The teacher limited software use to his giving a presentation so as to avoid demands and difficulties of students having to use it:

If I wanted the students to do it, it, it would take a long time in order for them to master the package and I think the cost benefit doesn't pay there... And there's huge scope for them making mistakes and errors, especially at this level of student. 
He was not persuaded that the educational returns from students learning to use the software were sufficient given a curriculum which was more factual than investigative, and with relatively few topics which would benefit from dynamic geometry treatment:

It's a difficult program for the students to master... The return from the time investment ... would be fairly small... And the content of geometry at foundation and intermediate level just doesn't require that degree of investigation. So they need to learn certain facts... but most of those facts can be learned quite well enough without Cabri.

\subsubsection{Case $P$}

This example, focusing on angle properties in various configurations, was nominated in these terms by the teacher concerned:

All of our angle work at [lower secondary] is done [with Cabri]... Most of the tasks are... designed with what we want to achieve from it in mind. So if we want them to see that the angles on a straight line add to 180 it's designed exactly for that purpose... So they should come to the right conclusion but... they feel that they've done it on their own and they've explained it.

A corresponding 50-minute lesson started with 15 minutes of activity led by the teacher, using an interactive whiteboard. This was followed by the students working in trios at a computer, guided by a teacher-devised worksheet, to investigate the angle sums of dynamic polygons that they themselves constructed (see Fig. 29.2).

\subsubsection{Developing Students' Broad Understanding of Space and Shape Through Exploring Dynamic Figures}

The emphasis of the investigation in this lesson was more on promoting students' broad understanding of shape and space than their knowledge of specific results:

Fig. 29.2 Figure used in Case $\mathrm{P}$ lesson

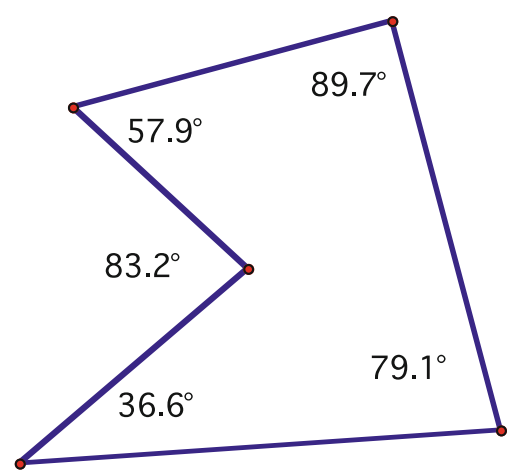


The work on angles in polygons is not so important; that is extension work, and we do it again, that topic, later in the year... So it's sort of a lead up for that as well. But in terms of key concepts, it's not really the curriculum topic that's important, but the understanding of space and shape in geometry, and how that works.

While other investigations which aimed at establishing specific results were more structured, this lesson was concerned with developing broader spatial awareness, and so was more fluid:

[This] lesson was more about them getting to know the software, them having an awareness of space, and thinking how shapes grow and what happens to some of the corners as they grow, and whether that's related to the shape. And that was much more fluid... I was a bit more adding on to the end of a topic, and you can be a bit wilder there, and not have to follow the curriculum as such.

\subsubsection{Giving Students Experience of Geometrically-Principled Interaction with the Software}

The teacher saw an important feature of the software as being the way in which its design around geometrical principles shaped student interaction with it:

The package is geometry-based, and it is from-first-principles geometry... One of the main parts of this lesson was that they could learn the software, and have some idea of how shapes and points relate to each other, and to see that the software works geometrically.

In particular, the teacher could build on students' experience of making use of the software to draw out the way in which they had been enacting geometrical principles:

When they were trying to measure the angle, that really brought out the idea of what is an angle... Just the action of doing it really made a fuss about that for them, and they really understood that angles, these three points that are on two lines, and what it means.

\subsubsection{Focusing Students' Attention on Mathematical Essentials Through Structured Software Use}

In more focused investigations, the teacher preferred to structure students' use of the software around the dragging of simple prepared figures in order to focus on mathematical essentials:

It does add complications, because it's quite a difficult piece of software. So that's why we structure the work so they just have to move points. So they don't have to be complicated by that, they really can just focus on what's happening mathematically.

She saw the ease with which figures could be dragged to create multiple examples as contributing to achieving this focus: 
As they move the shapes around, they can see what's actually happening, as if they were drawing it on a page, and doing different drawings. But it obviously removes the need for them to have to redraw things. So it's easier for the kids who find it hard to draw well. So it really helps them, and they can focus on the learning of how the angles match, and what they add up to.

\subsubsection{Supporting Students in Questioning Unexpected Results and Learning from Them}

The teacher sought to promote students' learning through supporting them in identifying and analysing the sometimes confusing way in which the software measured angles:

I wanted to draw attention to... how the software measures the smaller angle, thus reinforcing that there are two angles at a point and they needed to work out the other... Because a lot of them had found that they'd got the wrong answers, and [that] it measured the obtuse angle rather than the reflex angle, so I highlighted that, because that was important in terms of understanding the software. Next lesson, we'll talk a lot more about what we learned from it.

She valued anomalous situations of this type for developing students' critical mathematical thinking about results produced by the software:

For me, success is when the kids produce something and then say "This can't be right because it's not what I expect"... Because they're going to make mistakes. But if they look at it... they can sense that there's something wrong... So we talked about how we'd overcome that... I think that happened in slightly different ways around the room, but it was one of the key things that the kids learned, that you can't assume that what you've got in front of you is actually what you want, and you have to look at it... and question it, which is very powerful.

This reflected her wider emphasis on supporting students in thinking through apparently conflicting states of affairs to a coherent resolution:

Where there is a conflict like that and the child's not understood something or finds there's something not right, I question them about what's not right and why it's not right, and therefore what do they think it should be?... All the time [I'm] subconsciously thinking, what will challenge this child, what will open the door for them to take this step through.

\subsubsection{Case $Q$}

This example, focusing on the idea of the 'centre' of a triangle (see Fig. 29.3), was nominated in these terms by the teacher concerned:

We'd done some very rough work on constructions with compasses and bisecting triangles. And then I extended that to Geometer's Sketchpad on the interactive whiteboard... And we... bisected the sides of a triangle. And [the pupils] noted that [the perpendicular 
Fig. 29.3 Figure used in Case Q lesson

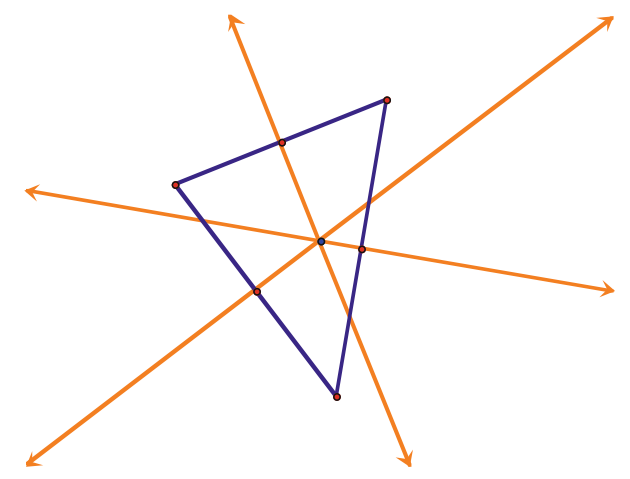

bisectors] all met at a point... And we moved it around and it wasn't the centre of the triangle. Sometimes it was inside the triangle and sometimes outside... So we had... the whole lesson, just discussing what's the centre of a triangle.

The corresponding lesson extended over two 45-minute sessions on consecutive days. Both sessions started with 10-20 minutes of teacher-led activity, using an interactive whiteboard. This was followed by student activity at individual computers, guided by a teacher-devised worksheet. In the first session, students themselves constructed a dynamic triangle and the perpendicular bisectors of its edges, in order to investigate the properties of the bisectors. In the second session, they investigated how changing the shape of the triangle affected the position of the point of concurrence.

\subsubsection{Giving Students Experience of Finding Rules and Patterns Within Abstract Geometry}

The teacher reported that the lesson followed on from work on construction by hand, extending this beyond the official curriculum:

Geometry's so vague in school maths at the moment... I mean the... national curriculum way would be to do the construction, and then on loci and stuff like that... [But] I went on more of the geometry way.

This involved learning to explore the properties of familiar shapes and conceptualise them in more abstract geometric terms:

The main thing is the idea that you can look at a shape that you're fairly familiar with and do things to it, and find new ideas. It's this idea of coming across abstract geometry and finding rules and patterns within it, which is what geometry's all about really.

The teacher's focus was more on students learning about geometrical exploration than on their mastering particular content: 
It's less about learning the actual facts, than about the ideas of exploring an abstract geometrical idea, and finding that there's lots of different rules... They will have manipulated shapes, they'll have got used to... the idea of trying to describe things. There's a lot of maths there that isn't directly learning facts, and I think that's a really important part of doing that sort of exercise.

\subsubsection{Emphasising Mathematical Rules Through Clarifying Student Instructions to the Computer}

The teacher saw the way in which the software required clear instructions to be given in mathematical terms as a key characteristic:

I always introduce Geometer's Sketchpad by saying "It's a very specific, you've got to tell it. It's not just drawing, it's drawing using mathematical rules.”... They're quite happy with that notion of... the computer only following certain clear instructions.

The teacher helped students to identify mistakes in their constructions and analyse them mathematically:

[Named student] had a mid-point of one line selected and... a perpendicular line to another, and he didn't actually notice... When I was going round to individuals; they were saying "Oh, something's wrong"; so I was [saying] "Which line is perpendicular to that one?"

He saw such difficulties as helping him to draw out the mathematical ideas at stake:

A few people... drew random lines... because one of the awkward things about it is the selection tool... [But] quite a few discussions I had with them emphasised which line is perpendicular to that edge... So sometimes the mistakes actually helped.

\subsubsection{Making Mathematical Properties Stand Out for Students Through Prompting Dragging}

The teacher noted the crucial part he played in making key mathematical properties stand out for students by prompting them to drag vertices of the dynamic trianglefor example, so as to bring out the concurrence of the perpendicular bisectors:

They didn't spot that they all met at a point as easily. I think it just doesn't strike them as being particularly unusual... I don't think anybody got that without some sort of prompting. It's not that they didn't notice it, but they didn't see it as a significant thing to look for.

Through similar prompting of dragging he helped students to appreciate how the position of the point of concurrence-inside or outside the triangle - could be related to the size of the largest angle of the triangle - acute or obtuse: 
It was nice to see the way that the point, the central point, went from inside to outside. They were able to move that around and look how the angle was changing. And what sort of rules... I led them very closely on that.

\subsubsection{Making Learning Less Vague Through Getting Students to Write a Rule Clearly}

Getting students to formulate their findings in explicit mathematical terms was an important issue for the teacher:

They've got to actually write down what they think they've learned. Because at the moment, I suspect they've got vague notions of what they've learnt but nothing concrete in their heads.

Accordingly, he sought to sharpen the precision with which students expressed their conclusions:

I was focusing on getting them to write a rule clearly. I mean there were a lot writing "They all meet" or even, someone said "They all have a centre"... So we were trying to discuss what 'all' meant, and a girl at the back had "The perpendicular bisectors meet", but I think she'd heard me say that to someone else, and changed it herself; "Meet at a point".

This refining of mathematical expression was assisted by the provisionality of the text box in which students entered accompanying sentences alongside their figures on the screen:

The fact that they had a text-box... and they could change it and edit it; they could actually then think about what they were writing, how they describe. I could have those discussions. With handwritten, if someone writes a whole sentence next to a neat diagram and you say..."Can you add this in?", you've just ruined their work. But with technology you can just change it, highlight it and add on an extra bit, and they don't mind.

\subsection{Cross-Cutting Themes}

The second stage of analysis sought to identify and conceptualise salient issues across cases, in broader analytic terms. The resulting themes identify important dimensions of practice, comparing the cases so as to characterise commonalities and contrasts in each dimension. Each subsection heading encapsulates a theme and extracts from quotations from the case outlines are included in the subsequent text to signal the evidential base for the theme. 


\subsubsection{Employing Dynamic Geometry to Support Guided Discovery}

In all of the cases, teachers appealed to some notion of learning through guided discovery, although the practical expressions of this idea differed. In one case, discovery by the whole class was closely guided by the teacher who found that "the technology helped a great deal" by making it easier for students to "spot the rule", and thus for the teacher "to get the correct response out of them", so that "you're not just telling them a fact, you're allowing them to sort of deduce it and interact with what's going on" [N]. In other cases, the classroom approaches involved more delegation to students working individually or in pairs, through tackling 'investigations' intended to develop their general understanding of shape and skills of inquiry. Ultimately, however, this activity was structured with the intention that students "should come to the right conclusion but... feel that they've done it on their own" [P]. In this respect, teachers acknowledged their important role in "drawing attention to" [P] and "prompting" [Q] target results.

\subsubsection{Evaluating the Costs and Benefits of Student Software Use}

In all of the cases teachers alluded to benefits of dynamic geometry-compared to classical manual tools - in facilitating extensive work with figures. However, there were important differences of perspective on whether the software should be used by students, leading to approaches based variously on avoiding, minimising, or exploiting its demands. In some cases, the teachers viewed dynamic geometry as "a difficult program for the students to master" with "huge scope for... mistakes and errors" $[\mathrm{N}]$; as "quite a difficult piece of software" which "does add complications" [P]. In one of these cases, then, the software was used only for teacher presentation on the grounds that "it would take a long time... for [students] to master the package" and "the return from the time investment... would be fairly small", so that "the cost benefit doesn't pay" [N]. In the other case where concerns about the accessibility of the software to students were expressed, unless the required figure was straightforward for students to construct for themselves, the normal pattern was "to structure the work, so [that students]... don't have to be complicated by that [and]...can just focus on what's happening mathematically" through providing them with a prepared figure [P]. Such concerns were not expressed in the final case [Q], perhaps because the teacher treated the construction of dynamic figures by students, and the development of their proficiency with the software, as a vehicle for developing and disciplining their geometrical thinking and expression. 


\subsubsection{Handling Apparent Mathematical Anomalies of Software Operation}

A further challenge for teachers was in handling apparent mathematical anomalies in the way in which the software operated, such as those arising when figures were dragged to positions where an angle becomes reflex (with the software displaying the measure of the associated acute or obtuse angle), or where an arithmetical relationship between angle measures was obscured by values being rounded. In one case, the teacher took great care to avoid exposing students to such anomalies, through vigilant dragging $[\mathrm{N}]$. The other case tackling the same type of topic (and indeed an identical topic in one lesson) provided a striking contrast. The teacher actually sought "to draw attention to... how the software measures the smaller angle" so that the apparent anomaly of measurement for reflex angles could be resolved through mathematisation, "thus reinforcing that there are two angles at a point and [that students] needed to work out the other" [P]. Moreover, in this case, the teacher considered that "one of the key things that the kids learned" was "that you can't assume that what you've got in front of you is actually what you want, and you have to look at it... and question it" [P]. These strategies differed, then, between - in the first case-concealing anomalies of software operation and-in the second case-capitalising on them for purposes of mathematical knowledge building.

\subsubsection{Supporting Learning Through Analysis of Mathematical Discrepancies}

Capitalising on such anomalies formed part of a wider teaching strategy in which "where there is a conflict like that and the child's not understood something or finds there's something not right", the teacher's preferred response was to "question them about what's not right and why it's not right" $[\mathrm{P}]$. The further case in which students worked with the software also emphasised the value of exploiting errors and anomalies so as to promote mathematical thinking and knowledge building. This teacher suggested that, where students encountered difficulties in constructing figures with the software, "sometimes the mistakes actually helped", by leading to discussions which drew out the mathematical ideas at stake [Q]. In the final-and contrasting - case, one of the reasons that the teacher offered for not having students themselves work with the software was the "huge scope for them making mistakes and errors". As already noted, this teacher sought to avoid exposing students to such anomalies by himself manipulating the software; and, while he reported that through questioning he would "pick on students that... may have a problem" and "carry on... trying to get the correct response out of them", this seems to have been more a means of managing lesson pace and progression than of supporting rethinking [N]. 


\subsubsection{Promoting Mathematically-Disciplined Interaction Through the Software}

In both the cases where students did construct figures using the software, teachers stressed the mathematical discipline involved. Experiencing "from-first-principles geometry" was intended to help students "see that the software works geometrically", and to give them "some idea of how shapes and points relate to each other" [P]. Likewise, the ideas of "the computer only following certain clear instructions" and of the software "not just drawing [but] drawing using mathematical rules" were made explicit to students [Q]. In addition, in this case, getting students to formulate their conclusions as a mathematically precise sentence was helped by using the software "text-box [to] change it and edit it... [so as to] actually then think about... how [to] describe" [Q].

\subsubsection{Privileging a Mathematical Register for Framing Figural Properties}

One case [Q] was distinctive in going beyond the official curriculum to a more classical emphasis on use of a geometrical register to frame and analyse figural properties. A concern that students should have experience of "finding rules and patterns" in "abstract geometry" led to them being asked to "write a rule clearly" as a means of "trying to describe things" in directly geometrical terms [Q]. By contrast, in the other cases, figural properties were inferred less directly from arithmetical patterns in the numerical measures generated by a dynamic figure. Because "you can pick up and drag these shapes around... so all the numbers are changing", students could "see [that] the angle doesn't change", or use "pairs of values... [to] deduce [for] themselves" the relationship between two angles [N]. By using a dynamic figure emphasising this more familiar arithmetical register - privileged by an official curriculum placing emphasis on the development of numeracy-students could "focus on the learning of how the angles match, and what they add up to" [P].

\subsubsection{Incorporating Dynamic Manipulation into Mathematical Discourse}

Finally, the case records show how mathematical discourse was developing to incorporate dynamic manipulation. Quite often, dragging was presented simply in terms of moving or changing a figure to generate discrete static examples: "move the triangle around and try different triangles within seconds" [Q]; "change it and you've got then an unlimited number of shapes" [P]. However, dragging was sometimes framed in more dynamic terms. Working in the directly geometrical 
register, for example, attention was drawn to "the way that the point, the central point, went from inside to outside [the triangle]" so that students "were able to move that around and look how the angle was changing" [Q]. Working in the more prevalent arithmetic register, attention was focused more sharply on the constancy, variation and covariation of measures; so that, for example, students "can actually see it getting dragged round, they see the angle doesn't change" or by "dragg[ing] these shapes around... so all the numbers are changing" $[\mathrm{N}]$.

\subsection{Discussion and Conclusion}

In line with the idea of interpretative flexibility, this study found important differences in teachers' 'constructions' of dynamic geometry, even if their teaching practices all appealed to some idea of employing the software to support guided discovery. Teacher assessments of the costs and benefits of software use by students were influenced by the extent to which such use was seen as promoting mathematically-disciplined interaction. Approaches to handling apparent mathematical anomalies of software operation depended on more fundamental pedagogical orientations towards analysis of mathematical discrepancies as a means of supporting learning. Dynamic manipulation entered mathematical discourse when dragging was used to focus attention on continuous variation rather than being treated as an efficient means of generating multiple static figures. In summary, then, not only is there a considerable gap between the aspirations of advocates for the educational potential of dynamic geometry and actual patterns of use in mainstream teaching but patterns of use vary markedly within that mainstream practice.

These teaching practices observed in England did share some basic characteristics that the ICMI Study on Mathematics Education and Technology identified in projects aiming to implement use of digital technologies at a national scale (Sinclair et al. 2010). In particular - in line with the ICMI findings - dynamic geometry was treated more as providing pedagogical support than as provoking curriculum change, and patterns of classroom (inter)activity tended to be less open than the accompanying pedagogical rhetoric suggested. In England, these characteristics reflected a statutory curriculum privileging the paper-and-pencil medium and classical instruments of hand construction; references to dynamic geometry in curricular guidance that were sporadic, optional and superficial; and high-stakes external assessment that excluded any use of dynamic geometry.

Indeed, recent developments in England have exacerbated these conditioning factors with a new curriculum in which the main substantive guidance on use of digital tools is now simply that "teachers should use their judgement about when ICT tools should be used" (Department for Education 2013, p. 2), with one subsequent fleeting reference to the possibility of using such tools to "derive and illustrate properties of... plane figures... using appropriate language and technologies" (p. 8), against a default assumption that classical tools should be privileged, for example, for "standard ruler and compass constructions" (p. 8). 
Consequently, recent graduate students that I have supervised have had great difficulty in tracking down examples of dynamic geometry use in English schools, with those found largely following the patterns exhibited in Cases $\mathrm{N}$ and P. Nevertheless, recently we have been able to describe one example of more developed practice in greater detail (Bozkurt and Ruthven 2016).

Under such circumstances, it is easier to envisage success for developments in teaching practice that treat dynamic geometry as a pedagogical aid in enriching the existing curriculum. In the English context, for example, such lines of development might encourage use of tasks which incorporate a richer system of related arithmetic patterns, and of figures which provide better visual support for directly geometric reasoning (for illustrations, see Ruthven 2005). However, a stronger aspiration for development would see dynamic geometry treated (for both curriculum and assessment) as a standard mathematical tool rather than as a marginal and occasional pedagogical aid. In the discussion after the lecture on which this chapter is based, there were suggestions that curriculum schemes (notably textbooks) in some educational systems (specifically California USA, Denmark and France) were now integrating use of dynamic geometry in a more systematic way. It would indeed be interesting to have analyses of such developments reported at future ICME conferences, examining the manner in which dynamic geometry is interpreted and its use developed, both in the curriculum materials themselves and in the teaching practice associated with their use.

In effect, the field of mathematics education is itself still 'constructing' dynamic geometry. With the many varieties of dynamic geometry software, convergence towards mature common standards remains limited (Mackrell 2011). However a major European project, Intergeo, has sought to facilitate exchange and use of dynamic geometry resources by teachers through creating an online repository with the potential to enrich the readily available range of tried and tested dynamic tasks (Kortenkamp and Laborde 2011). While these resources were developed by individual members of the community, the project sought to enhance their collective usability in three particular ways:

- by specifying a common file format based on open standards, so enabling teachers to employ their software of choice;

- by tagging each resource with metadata, so helping teachers to search for relevant resources;

- by developing a standard quality questionnaire to be completed by users of a resource, so providing prospective users with reviews.

Although such developments are of considerable value, they have also highlighted continuing obstacles. Following the introduction of the quality questionnaire, for example, the overwhelming majority of responses were made without the reviewer actually having trialled the resource in the classroom (Trgalova et al. 2011).

Indeed, it is arguable that the field of mathematics education has only scratched the surface in generating the knowledge needed to support a more thorough 
integration of dynamic geometry. Some areas where productive development could take place are clear. Arzarello et al. (2002) have identified a rich range of dragging techniques, each associated with particular patterns of geometrical reasoning. However, in the teaching practices observed in English schools, only a small subset of these techniques were used, largely tacitly: Dragging defining points of a figure to generate multiple examples; Dragging defining points of a figure to explore patterns of dynamic (co)variation. Development of this aspect would be supported if the field were to build a tighter mathematical theorisation of dragging, establish a more widely accepted register for discussing it, and create well-tested curricular sequences (with supporting didactical analyses) which make effective use of a range of dragging techniques and provide widely accepted norms for these. Developing a robust practical framework of this type would provide a firmer basis for developing more reflective use of a richer repertoire of dragging techniques by teachers and students.

Likewise, Laborde (2001) has identified an important gradation in curricular scenarios which make use of dynamic software, increasingly challenging for teachers to conceive and implement:

- Facilitates material aspects of familiar task: e.g. constructing a diagram showing a triangle and its perpendicular bisectors.

- Assists mathematical analysis of familiar task: e.g. through dragging vertices of a dynamic triangle to identify concurrence of the perpendicular bisectors as an invariant property.

- Substantively modifies a familiar task: e.g. through dragging vertices of a dynamic triangle to identify conditions under which its circumcentre is positioned internally or externally.

- Creates task which could not be posed without dynamic software: e.g. through constructing circles sharing a common free centre but each passing through a different vertex of the triangle, then dragging that free centre to identify positions where the circles become concurrent (see Fig. 29.4).

The challenge here is not just to devise dynamic geometry scenarios at those latter two levels which go beyond the classical curriculum. Rather it is to move beyond creating relatively isolated scenarios to establishing well-articulated sequences of scenarios which provide a sound basis for developing the mathematical and technical (i.e. instrumental) knowledge of students in a coordinated and progressive manner. (For example, one can imagine a curricular progression in which the task shown in Fig. 29.4 occurs earlier in a sequence leading to the tasks used in Case Q). More thoroughgoing integration of dynamic geometry into the curriculum as a mathematical tool depends on the development of progressive sequences of this type, and of a principled basis for their design (see, for example, Coutat et al. 2016). 

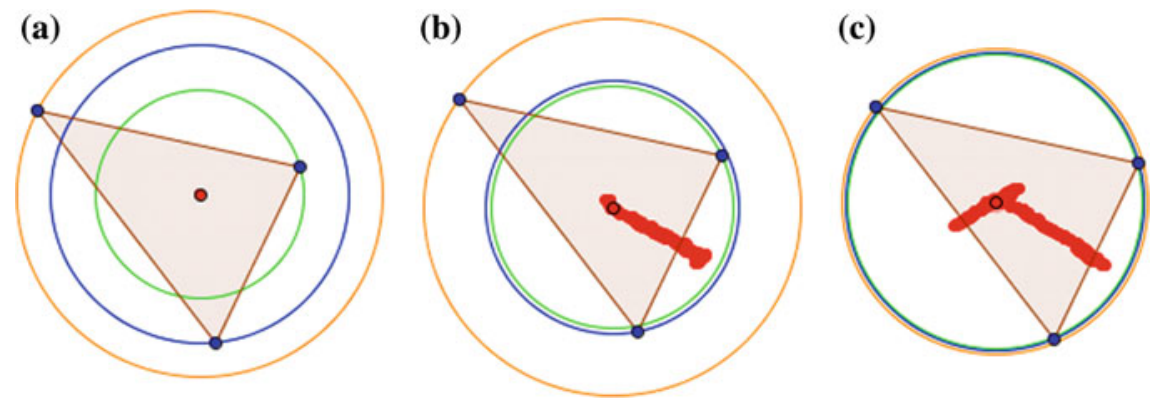

Fig. 29.4 a Construction of concentric circles through individual triangle vertices; $\mathbf{b}$ dragging of free centre to identify locus for concurrence of two circles; and then $\mathbf{c}$ further dragging to identify position for concurrence of all three circles (and thus centre of the circumcircle of the triangle)

Acknowledgements Funding for the study discussed in this chapter came from the UK Economic and Social Research Council (R000239823). The research was carried out in collaboration with Sara Hennessy and Rosemary Deaney. Thanks are also due to the participating teachers. This chapter draws on and adapts material from previously published work (Ruthven et al. 2008; Ruthven 2012). Finally, thanks go to the ICME editor and reviewers for their helpful suggestions.

\section{References}

Arzarello, F., Olivero, F., Paola, D., \& Robutti, O. (2002). A cognitive analysis of dragging practises in Cabri environments. ZDM, 34(3), 66-72.

Ball, D. L., \& Cohen, D. K. (1996). Reform by the book: What is-Or might be-The role of curriculum materials in teacher learning and instructional reform. Educational Researcher, 25 (9), 6-8 \& 14.

Becker, H., Ravitz, J., \& Wong, Y. (1999). Teacher and teacher-directed student use of computers, teaching, learning, and computing: 1998 National Survey Report \#3. Centre for Research on Information Technology and Organizations, University of California Irvine.

Bozkurt, G., \& Ruthven, K. (2016). Classroom-based professional expertise: A mathematics teacher's practice with technology. Educational Studies in Mathematics, 94(3), 309-328.

Chazan, D., \& Yerushalmy, M. (1995). Charting a course for secondary geometry. In R. Lehrer \& D. Chazan (Eds.), New directions in the teaching and learning of geometry (pp. 67-90). Hillsdale, NJ: Lawrence Erlbaum.

Coutat, S., Laborde, C., \& Richard, P. R. (2016). L'apprentissage instrumenté de propriétés en géométrie: propédeutique à l'acquisition d'une compétence de démonstration. Educational Studies in Mathematics, 93(2), 195-221.

Department for Education and Employment [DfEE]. (2001). Key stage 3 national strategy: Framework for teaching mathematics. London: DfEE.

Department for Education [DfE]. (2013). Mathematics programmes of study: Key stage 3. London: DfE.

Goldenberg, E., Scher, D., \& Feurzeig, N. (2008). What lies behind dynamic interactive geometry software? In G. Blume \& M. Heid (Eds.), Research on technology in the learning and teaching of mathematics: Cases and perspectives (pp. 53-87). Greenwich, CT: Information Age.

Hoyles, C., Foxman, D., \& Küchemann, D. (2001). A comparative study of geometry curricula. London: Institute of Education. 
Kaiser, G. (2002). Educational philosophies and their influence on mathematics education-An ethnographic study in English and German mathematics classrooms. ZDM, 34(6), 241-257.

Kline, R., \& Pinch, T. (1999). The social construction of technology. In D. MacKenzie \& J. Wajcman (Eds.), The social shaping of technology (pp. 113-115). Buckingham: Open University Press.

Kortenkamp, U., \& Laborde, C. (2011). Interoperable interactive geometry for Europe: An introduction. ZDM, 43(3), 321-323.

Laborde, C. (2001). Integration of technology in the design of geometry tasks with Cabri-Geometry. International Journal of Computers for Mathematical Learning, 6(3), 283317.

Laborde, C., \& Laborde, J.-M. (2008). The development of a dynamical geometry environment: Cabri-géomètre. In G. Blume \& M. Heid (Eds.), Research on technology in the learning and teaching of mathematics: Cases and perspectives (pp. 31-52). Greenwich, CT: Information Age.

Mackrell, K. (2011). Design decisions in interactive geometry software. ZDM, 43(3), 373-387.

Remillard, J. (2005). Examining key concepts in research on teachers' use of mathematics curricula. Review of Educational Research, 75(2), 211-246.

Ruthven, K. (2005). Expanding current practice in using dynamic geometry to teach about angle properties. Micromath, 21(2), 26-30.

Ruthven, K. (2012). The didactical tetrahedron as a heuristic for analysing the incorporation of digital technologies into classroom practice in support of investigative approaches to teaching mathematics. ZDM, 44(2), 627-640.

Ruthven, K., Hennessy, S., \& Deaney, R. (2008). Constructions of dynamic geometry: A study of the interpretative flexibility of educational software in classroom practice. Computers and Education, 51(1), 297-317.

Sinclair, N., Arzarello, F., Gaisman, M. T., Lozano, M. D., Dagiene, V., Behrooz, E., et al. (2010). Implementing digital technologies at a national scale. In C. Hoyles \& J.-B. Lagrange (Eds.), Mathematics education and technology-rethinking the terrain (pp. 61-78). New York, NY: Springer.

Trgalova, J., Soury-Lavergne, S., \& Jahn, A. P. (2011). Quality assessment process for dynamic geometry resources in Intergeo project. ZDM, 43(3), 337-351.

Open Access This chapter is licensed under the terms of the Creative Commons Attribution 4.0 International License (http://creativecommons.org/licenses/by/4.0/), which permits use, sharing, adaptation, distribution and reproduction in any medium or format, as long as you give appropriate credit to the original author(s) and the source, provide a link to the Creative Commons license and indicate if changes were made.

The images or other third party material in this chapter are included in the chapter's Creative Commons license, unless indicated otherwise in a credit line to the material. If material is not included in the chapter's Creative Commons license and your intended use is not permitted by statutory regulation or exceeds the permitted use, you will need to obtain permission directly from the copyright holder.

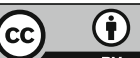

